\title{
The push of stigma: a qualitative study on the experiences and consequences of sexuality stigma among same-sex attracted men in Harare, Zimbabwe
}

\section{Oliver Mutanga \& Kåre Moen}

Institute of Health and Society, University of Oslo, Oslo, Norway

\begin{abstract}
This paper describes experiences of sexuality stigma among same-sex attracted men in Zimbabwe and analyses the consequences of such experiences for healthcare seeking. It draws on qualitative research carried out in Harare in 2017, which included in-depth interviews with sixteen gay and bisexual men, and key informant interviews with three representatives of organisations that work with gay men. There were numerous stories about sexuality stigma in the study participants _ social environments, including at home, in local communities and in healthcare facilities.

We first offer a description of these and then go on to trace the implications of stigma on the relations between men who have sex with men on the one hand and the healthcare sector on the other. We conceive of stigma as a pushing force that exerts pressure on and in these relations, and identify five types of consequences of this. Stigma works to (1) produce geographical shifts in healthcare, (2) promote private over public care, (3) compartmentalise healthcare (with dedicated providers for queer persons), (4) deprofessionalise care, and (5) block access to appropriate healthcare altogether for some same-sex attracted men. Most of these consequences have negative implications for preventive or treatment-focused HIV programming.
\end{abstract}

\section{KEYWORDS}

Healthcare seeking; same-sex attracted men; stigma; Zimbabwe

\section{Introduction}

Men who have sex with men in Africa are at a high risk of HIV infection as a result of a variety of factors, including the conduct of healthcare staff (Maleke et al. 2017; Nkambule et al. 2017). For a long time, same-sex attracted men were left out of most HIV-related research and programming in Africa (Beyrer et al. 2010). The overwhelming scale of the heterosexual HIV epidemic, coupled with political, social and cultural barriers against homosexual practices, severely delayed the development of a same-sex-focused response to HIV in most parts of the continent (Mclntyre 2010). International organisations in the African HIV epidemic also did not address the epidemic among gay and other same-sex practising men for a long time (Moen et al. 2012). 
Sub-Saharan Africa still accounts for two-thirds of the world's total new HIV infections (Kharsany and Karim 2016). In East and Southern Africa, men who have sex with men are among the groups that experience high HIV prevalence. One in three is living with HIV, and in 2014, $6 \%$ of new HIV infections occurred among men in this group (UNAIDS 2017a). Given the continued burden of HIV on countries, communities and individuals, a better understanding of the health care needs and challenges among men who have sex with men is an urgent priority. It will be impossible to reach UNAIDS's three zero goals (zero new infections, zero HIV related deaths and zero discrimination) without strengthened HIV programming in this segment of the population (Haghdoost and Karamouzian 2012).

One of the reasons for the high prevalence of HIV among men who have sex with men is stigma enacted in families, local communities and healthcare facilities (Larsson et al. 2017; Ross et al. 2015; Stojisavljeciv, Djikanovic, and Matejic 2017). In South African townships, for example, Lane et al. (2008) found that same-sex attracted men felt that their options for non-stigmatising sexual healthcare services were limited by homophobic verbal harassment by healthcare staff. In Malawi, many men reported stigmatisation and fears of sexual orientation disclosure (Ntata, Muula, and Siziya 2008). Fay et al. (2011) have found strong associations between men's experiences of discrimination and their fear of seeking healthcare services. Furthermore, the vilification of homosexuals by some national presidents has contributed to seriously inadequate healthcare interventions (Nyanzi 2013). Significantly, some studies have also shown that the stigmatisation of men who have sex with men is associated with poor mental health, increased sexual risk behaviour and a higher prevalence of sexually transmitted infections (Arreola et al. 2015; Maulsby et al. 2014; Parker et al. 2018).

Previous scholarship has dealt with HIV related stigma in Zimbabwe (Busza et al. 2018; Campbell et al. 2011; Ferris et al. 2019; Duffy 2005; O'Brien and Broom 2014), and several previous publications have referred to experiences of stigmatisation and discrimination among men who have sex with other men (e.g. Hunt et al. 2017; Mabvurira et al. 2012; Matsikure 2009). In this paper, we describe experiences of sexuality stigma among a diverse group of queer men in the Zimbabwean capital and analyse the consequences of these experiences for their relationships with the healthcare system and their healthcare seeking.

\section{Context}

Zimbabwe has an overall HIV prevalence of nearly 14\% (UNAIDS 2016). In 1999, the Zimbabwean government established the AIDS levy, funded through $3 \%$ payee and corporate taxes, that goes to support the national HIV response (Zimbabwe Ministry of Health and Child Care and National AIDS Council 2015). In parallel with collaborative efforts by the government and other stakeholders, the number of new HIV infections in Zimbabwe has decreased by $49 \%$ since 2010, and AIDS-related deaths have fallen by $45 \%$ (UNAIDS 2016). While the national HIV policy framework has acknowledged that men who have sex with men face a heightened risk of HIV, until recently, there had been no specific public response to the HIV epidemic in this 
group. In 2018, however, the government launched a training programme for healthcare providers on key populations in the HIV epidemic, including men who have sex with men (Ministry of Health and Child Welfare 2018). The estimated HIV prevalence in the latter group is 31\% (UNAIDS 2017b).

There have been many studies in Zimbabwe focusing on same-sex practising men. Among important contributions are Epprecht (1998, 1999, 2004, 2005, 2012, 2013), Gunda (2010, 2011); Goddard (2004); Hunt et al. (2017), Muparamoto (2018), Phillips (1997, 2009), Van Klinken and Chitando (2016), and, Van Klinken and Gunda (2012). These studies have explored the gay rights movement in Zimbabwe; historical aspects of same-sex sexuality; religion and same-sex sexuality; and culture, human rights and homosexuality. This literature indicates that negative attitudes towards same-sex practising men are deeply embedded in Zimbabwe's social and historical forces. We variously use the terms gays, queer men, men who have sex with men and same-sex practising men in this paper as a way of reflecting the diversity of labels and understandings in circulation.

\section{Conceptualising stigma}

Stigma is a term that is frequently used and applied in many different fields. This has led to different interpretations - and perhaps a loss of clarity - in the concept. The work of Goffman (1963) and Link and Phelan (2001) informs our understanding of stigma in this paper. Goffman (1963) popularised the concept of stigma in the academic field. He explained that when a stranger is present before us,

"evidence can arise of his possessing an attribute that makes him different from others in the category of persons available for him to be, and of a less desirable kind - in the extreme, a person who is quite thoroughly bad, or dangerous, or weak. He is thus reduced in our minds from a whole and usual person to a tainted, discounted one. Such an attribute is a stigma, especially when its discrediting effect is very extensive..." (Goffman 1963, 11-12).

Of significance in Goffman's conceptualisation is the understanding that stigmatisation is a process involving relationships between an attribute, stereotyping and loss of status (Link and Phelan 2001). Building on Goffman's work, Link and Phelan (2001, 377) expanded the conceptualisation of stigma. For them, stigma exists when "labeling, stereotyping, separation, status loss, and discrimination occur together in a power situation that allows them." In labelling, people distinguish human differences and articulate them through the use of labels, then in stereotyping labelled individuals are linked to undesirable characteristics and put into separate categories to create an "us" and "them" distinctions. Labelled and otherised individuals lose status as they are driven down in status hierarchies; and discrimination is manifested when they are isolated or denied access to some goods and services leading to unequal outcomes (Link and Phelan 2001). We adopt this conceptualisation in this paper as we find it offers a multifaceted and multilevel understanding of stigma. 


\section{Research design and methods}

We carried out qualitative interviews with 16 men who had regular or occasional sex with other men in Harare, Zimbabwe. They were recruited through 1) persons with prior knowledge of the lesbian, gay, bisexual, trans and intersex (LGBTI) community, 2) organisations working with the LGBTI community and 3) snowballing (recruited participants were asked to invite other potential study participants from their personal networks).

The organisations mentioned enquired among their members who defined themselves as men who had sex with other men and were interested in joining the study. To lessen the chance of feeling coerced to participate, we approached those who had indicated their willingness to let us do so. Our aim was to recruit persons with diverse backgrounds, and we managed to have study participants from both low and high income backgrounds; persons who were employed, self-employed and un-employed; persons self-identifying as both gay and bisexual; and persons with ages ranging from 19 to 39 years.

In addition to in-depth interviews, we carried out three key informant interviews with representatives of organisations that worked with same-sex attracted men in Harare. These interviews provided contextual information to the study and perspectives on sexuality stigma facing same-sex attracted men in Harare. The fieldwork was carried out by the first author, who shares a national and cultural background with the study participants. Interviews were conducted in either English or Shona (one of the main local languages), and were audio recorded and transcribed verbatim. We also collected and reviewed secondary data, including national and international HIV related plans and strategies.

Transcribed data were imported into NVivo 11, a software programme that organises qualitative data, in which we created tentative descriptive codes that became themes. For this article, we coded experiences of stigma and actions taken in response to stigmatisation. Below, we first trace the different situations in which stigma was reportedly experience by same-sex attracted men, and thereafter go on to explore some of the ways in which experiences of stigma contributed to shape the relationships (or lack thereof) between men who have sex with men and healthcare services and healthcare professionals.

The necessary approvals were obtained from the Norwegian Centre for Research Data (NSD) in Norway (52794) and the Medical Research Council of Zimbabwe (MRCZ/A/2159) before commencing the study.

\section{Findings}

This section describes the study participants' experiences with and responses to stigma and has two parts. The first traces experiences of stigma in various domains of social life, whereas the second looks at the implications of stigma on study participants' healthcare-seeking behaviour. 
Before we start this exploration, it is important for us to stress that stigma was not all that the study participants experienced. Participants 1 also described how families and friends, community members and healthcare staff positively supported their needs and contributed constructively to deal with their circumstances. There is a tendency in the literature on Africa and same-sex relations to overlook this latter aspect of experienced realities, and this may contribute to misrepresent circumstances. We hope to return to other aspects of the experiences of same-sex attracted men in Harare elsewhere, but in this paper, we limit ourselves to experiences and consequences of stigma.

\section{Experiences of stigma}

There were numerous stories about stigma in the study participants_immediate social environments. Some men told of negative reactions of various kinds at home. For example, when Jim's father heard about his son's sexual orientation, he could not at all accept it. He linked it to evil spirits and forced his son to visit traditional healers in an effort to cure him of them. However, nothing changed, and Jim was disowned and chased away from the family home. Through this action, the father isolated his son from the social context of the family. Around the same point in time, Jim lost some of his friends, who, he explained, did not want to be associated with a homosexual.

Study participants also described incidents in which they were stigmatised by members of their wider local communities. David, for example, was beaten up by a neighbourhood person who shouted that he was an embarrassment to the community because of his sexuality. When David reported this at the local police station, no officer was willing to take up the case. In this case, labelling (homosexual), stereotyping (embarrassment to the community), discrimination (violence and not taking the case) contributed to physical injury, status loss and lack of protection.

Men also faced discrimination in healthcare facilities. For example, one key informant recounted how one of their group members went to the clinic and disclosed that he had anal ulcers, in response to which the nurse started counselling him using the Bible. The patient explained to her that he was a Christian, but that he had come only for the health services. The nurse responded, 'even if we treat you, but you continue with your demonic acts, you will continue getting sick and you will waste our medication'. In this case, the healthcare provider enacted stigma when summoning the Bible and her Christian beliefs, imposing them on the patient, and denying him medical treatment.

Apart from concrete lived experiences of stigmatisation, there was also structural stigma and discrimination. Among these were constraints imposed by the Criminal Law (Codification and Reform) Act 2004, which outlaws sexual acts between men but not self-identifying as an LGBTI person (Hunt et al. 2017):

"Any male person who, with the consent of another male person, knowingly performs with that other person anal sexual intercourse, or any act involving physical contact other than anal sexual intercourse that would be regarded by a reasonable person to be an indecent act, shall be guilty of sodomy and liable to a fine up to or exceeding level fourteen or imprisonment for a period not exceeding one year or both." (Constitution of Zimbabwe 2004, 50). 
Ongoing political discourse in Zimbabwe is labelling, stereotyping, separating and discriminatory towards same-sex attracted men. The late President Mugabe was widely known for his public denouncement of homosexuals, among other things labelling such persons as "worse than pigs and dogs" (Shoko 2010, 644). Although the political landscape in Zimbabwe has changed since the ousting of the former president, it may still be too early to judge to what degree the official stance on samesex relations will change. Prior to the elections in July 2018, officials from the ruling ZANU-PF party met with representatives of the LGBTI community in a bid to see how they can best relate with one another (New Zimbabwe 2018). However, in an interview around the same time (CNN 2018), the country's new president, Mr Mnangagwa, told Richard Quest that: "In our Constitution, it [same-sex acts] is banned-and it is my duty to obey my Constitution." Recently, a teacher at a prestigious private school was forced to resign after a furious backlash from parents following his admission to being gay (Duff 2018).

How study participants dealt with experiences of stigma varied. Some passively accepted accepting discriminatory actions whereas others took action to counter the negative consequences of stigma, either individually or in groups collective activism. Some remained self-confident whereas others shared experiences of low self-esteem and self-deprecatory thoughts, e.g. dwelling on periods in their lives when they made efforts to be heterosexual. For stigma scholars, this would be referred to as internalised stigma (Fitzgerald-Husek et al. 2017), i.e. acceptance of stigma as being true and applicable to oneself because of perceived and enacted stigma (Fekete, Williams, and Skinta 2018).

Simba, for example, considered himself gay, but had not disclosed his sexuality to his family and most of his friends. Instead, he was hiding it as he felt that being gay was wrong according to his Christian faith. He said that he had visited churches with the hope that church leaders would be led by the spirit and notice that he had a homosexual 'spirit' and remove it from him, but the leaders did not seem to notice any homosexual 'spirit', and nothing was done. Simba clearly felt ashamed and that there was something about him that was not as it should be.

\section{Implications of stigmatisation for healthcare seeking behaviour}

In what follows, we trace the implications of stigma on the relations between men who have sex with men in Harare on the one hand and the providers of healthcare on the other. We use the metaphor of pushing to conceive of the consequences of stigma for these relations. Stigma exerts pressure that contributes to shape healthcare seeking in certain specific ways. We identified five types of such 'pushing forces'.

\section{A geographical push}

One consequence of enacted, perceived and felt stigma was an ongoing subtle geographical shift in the landscape of healthcare. Many same-sex practising men 
simply did not want to seek healthcare in their own neighbourhoods, but rather sought help and care further away.

I would never go at the local clinic. There is discrimination and stigma that comes with being a man who sleeps with other men. I would not even try to go there. I go to clinics in other areas (Alfred)

While it seems sensible that people would visit their nearest public healthcare facilities (among other reasons because this offers shorter travel distances and ultimately lower costs), this was not always the case for queer men in Harare. As a reaction to stigma from healthcare staff, men like Alfred chose not to seek help from the local facilities. Instead, they visited services at healthcare facilities located further away from their places of residence.

Of course, seeking healthcare services at facilities further away was not a guarantee of more professional and friendly treatment. However, study participants argued that even if stigma occurred at the healthcare facility, it would most likely stay within that health facility. This was not assured in healthcare facilities in their own neighbourhoods, where either the staff or other clients might pick up things that had transpired and spread it around the community.

\section{Push towards lay advice and self-treatment}

A second kind of shift was towards greater reliance on lay advice and self-treatment. Faced with a (potentially and de facto) stigmatising health care system, men at times preferred to shy away from professional healthcare services and sought lay advice and help instead. While some problems were successfully sorted in this way, this was not always the case. Joshua, for example, had not managed to treat his own piles.

Although by no means a specifically gay or HIV-related condition, Joshua (and several other study participants) were worried that piles could serve as a sign they were engaging in receptive anal sex and hesitated to bring it up with healthcare providers.

I told a friend that I have a problem of haemorrhoids and he said that I should apply petroleum jelly after taking bath. I asked other guys and they said that they had been advised to apply candle wax, another one showed me a herb and another said he was told to sit on salt. (Joshua)

While help and advice from friends and family members is common for most citizens, stigma worked to make this route extra meaningful among men who had sex with men and contributed to a relative shift away from the professional sector towards the lay sector of the healthcare system. This was also the case regarding the sourcing of health information. When men lacked knowledge about sexually related issues (which the formal healthcare system did not provide them with), study participants often had to rely on knowledge gained from their peers and from the Internet.

\section{Push towards private healthcare}


A third consequence of stigma was a push away from public healthcare facilities in the direction of private services. Tapiwa and Tino, for example, two of the study participants who came from affluent residential areas of Harare, said that they used private doctors to avoid stigma in publicly owned health facilities. The situation was perceived to be much different in private care:

"They are gay friendly, and they take you through every step, explaining everything clearly." (Tapiwa)

Fortunately, Tapiwa could afford to pay for private healthcare as he came from a well to do family, and private care did not severely affected his personal economy. However, among men who were not equally well off, but paid for private healthcare although they could only barely afford it, the push towards private healthcare providers had important implications for their overall financial situation.

\section{Push towards dedicated healthcare}

A fourth kind of consequence was a push towards health service providers who had entered into particular agreements with organisations offering support to the LGBTI community.

We wrote to different doctors, introducing ourselves and requesting services for our members. Some responded and others did not. We brought a specialist from South Africa who trained those who had responded positively, working with the LGBTI community. From there we started referring our members to the trained doctors whom we pay. (Lillian, LGBTI activist)

Men in this study used private healthcare facilities which, in collaboration with some LGBTI organisations, offered healthcare support to the LGBTI community. Study participants mentioned the positive role played by these clinics, which offered free-ofcharge educational support and services (including HIV testing \& counselling, condoms, lubricants, PEP, and PrEP) in a supportive and friendly atmosphere.

\section{Push away from necessary healthcare in the first place}

The most serious consequence of stigma was that it pushed men away from necessary care in the first place. Being in a stigmatising environment had both social and psychological effects on men who have sex with men. It bred uncertainty and sometimes this had the consequence that necessary healthcare was not obtained at all. For example, although sexually active, some study participants had never been tested for HIV as they avoided situations that exposed them to stigma.

I had a friend who was very sick and they took him to the hospital. They wanted to test [for] TB and HIV, he got up and told them that he did not come there for that. They tried to convince him to test, but he refused, they had to treat what they could see. (Maxwell)

Some men did not seek care even when there was a strong need to do so. At times, this was linked to fatal outcomes. Some of our members do not go to clinics for fear of being stigmatised. This year one of our members died. He had anal ulcers and we 
referred him to a certain facility then they referred him to another healthcare facility. Unfortunately, I think that day there were no homosexual-friendly trained staff and the receptionist called her friends, even the cleaners, to come and see this boy. He went home without getting any medication and he stopped going to the clinic to get his ARV medication and the ulcer spread and became cancerous, he died. (Lillian, LGBTI activist).

As told, this story draws our attention to the potentially very serious consequences that can follow from stigma and discrimination in the clinic. In this case, the stares and comments of curiosity seekers among staff in the health facility drove a young HIV positive man away from the clinic and from his ARV medication. His subsequent death was associated with this occurrence.

\section{Discussion}

Stigmatisation of men who have sex with men has been well documented globally. We have tried to contribute to this documentation by exploring stigma among same sex attracted men in Harare and identifying the consequences experiences of stigma have for their interaction with the healthcare sector.

Five main consequences were highlighted. We conceive of them as a set of pushing forces that contribute to shape health-seeking behaviour in specific ways. In short, what we have seen is that stigma works to produce geographical shifts in healthcare, promote private over public care, increase individuals_healthcare-related expenditures, compartmentalise healthcare (with dedicated providers for queer persons), deprofessionalise care and block access to appropriate healthcare altogether for some same-sex attracted men. It would seem to be of importance that key stakeholders, including the National AIDS Council and the Ministry of Health and Child Care, be aware of these five consequences and take them into consideration as they work to develop policies and programmes for the future. Our findings are not, of course, statistically representative, so there is no way of knowing how common the described consequences may be. However, what the study participants show us is that they are at work, and that their negative implications for access to healthcare in general, and to HIV related services in particular, are far from trivial. While some of the pushing forces of stigma make it more difficult to obtain preventive and curative services at appropriate times and affordable cost, others work to exacerbate social inequalities in health.

The emergence of dedicated healthcare facilities for men who have sex with men is both popular among and immensely helpful for many men in Harare. Yet, the establishment of such facilities may not be without their own potential challenges. One may relate to sustainability, since these services are funded by external sources and rely on ongoing availability of donor commitment. Will this last? Another may be whether dedicated "gay healthcare", instead of challenging the stigmatisation of men who have sex with men, could contribute to sustain 'othering' and social exclusion. If one assumes that personal contact with the other can represent a way through which othering processes may be challenged and amended, it would clearly not be a good 
thing if all queer clients should have disappeared from the mainstream healthcare system. Finally, since dedicated LGBTI care is only available in Harare and other large towns, it is a solution that may not easily assist those who live in other locations.

To address the stigma directed towards men who have sex with men, a variety of interventions are required. Some of them should be enacted by the professionals that serve the healthcare needs of Zimbabweans. Doctors are bound by professional ethics codes that require them to provide medical care irrespective of their patients behaviours and practices. Already the Hippocratic oath stated that "Into whatsoever houses I enter, I will enter to help the sick" (National Library of Medicine 2002) and the ethical code of the World Medical Association, of which the Zimbabwe Medical Association is a member, continues to call for respecting the rights and preferences of patients (World Medical Association 2006). Similarly, the Nursing Council of Zimbabwe is a member of the International Council of Nurses whose ethical codes (Smith and Mafa 2010) prescribe sensitivity to the values, customs and beliefs of patients.

The national government also has an important role to play. Although Zimbabwean law still criminalises same-sex acts, section 76 of the Constitution guarantees every citizen the right to health, including basic care, timely and appropriate healthcare, and access to health-related information. As we have shown, stigma works to contravene these basic principles. While some of the work the government could do to help rectify this will take time, other things could be done right away. Through the AIDS levy, Zimbabwe has built a unique funding model for HIV-related programming. However, while funding has been provided for interventions targeting other key populations, there has so far been silence regarding same-sex practising men. By including this population in projects funded by the AIDS levy, the government would be sending the message that men who have sex with men should not be excluded from, but be treated like others with respect to access to healthcare.

Interestingly, Goffman's (1963) famous theorising of stigma, referred to earlier, takes as a starting point "While a stranger is present before us", perhaps giving the impression that stigma may be linked to our unfamiliarity with the (soon to be) stigmatised person.

While this is sometimes the case, some of the other participants in this study described experiences of stigma that were linked to persons they knew very well. Under such circumstances, it is clearly not the person as such that is a "stranger" to the other, but rather an aspect of his or her subjectivity. While Goffman is right, it seems that there is something about stigmatised identities that renders people strangers in our minds. This cannot be answered in this paper but warrants further investigation.

Finally, LGBTI organising in Zimbabwe would certainly seem to have an important role to play, with respect to stigma as well as with respect to health care access. Community solidarity may work to challenge internalised stigma, community voices may work to challenge taken-for granted (mis)conceptualisations of minorities, and community action may contribute to shift political, bureaucratic and professional attitudes.

\section{Note}


1. To maintain confidentiality, this and all other names given to study participants in this paper are pseudonyms.

\section{Acknowledgements}

We are also grateful to Nelson Muparamoto who was very helpful and acted as a discussion partner and an advisor during fieldwork.

\section{Disclosure statement}

No potential conflict of interest was reported by the authors.

\section{Funding}

The research leading to these results has received funding from the European Union Seventh Framework Programme (FP7-PEOPLE-2013-COFUND) under grant agreement n_609020 - Scientia Fellows. 


\section{References}

Arreola, S., G. M. Santos, J. Beck, M. Sundararaj, P. A. Wilson, P. Hebert, K. Makofane, T.D. Do, and G. Ayala. 2015. "Sexual Stigma, Criminalization, Investment, and Access to HIV Services among Men Who Have Sex with Men Worldwide." AIDS \& Behaviour 19: 227-234.

Beyrer, C., S. D. Baral, D. Walker, A. L. Wirtz, B. Johns, and F. Sifakis. 2010. "The Expanding Epidemics of HIV Type 1 among Men Who Have Sex with Men in Low- and Middle-Income Countries: Diversity and Consistency." Epidemiologic Reviews 32 (1): 137-151. doi:10.1093/epirev/mxq011

Busza, J., V. Simms, C. Dziva Chikwari, E. Dauya, T. Bandason, M. Makamba, G. McHugh, and R. A. Ferrand. 2018. "It Is Not Possible to Go inside and Have a Discussion': How Fear of Stigma Affects Delivery of Community-Based Support for Children's HIV Care." AIDS Care $30 \quad$ (7): 903-909. doi:10.1080/09540121.2018.1445826

Cable News Network (CNN). 2018. Richard Quest Has Tough Questions for Zimbabwe's New President. https://www.youtube.com/watch?v=Z8ls1ddrpa8\&t=20s

Campbell, C., M. Skovdal, C. Madanhire, O. Mugurungi, S. Gregson, C. Nyamukapa. 2011. 'We, the AIDS People...' How Antiretroviral Therapy Enables Zimbabweans Living with HIV/AIDS to Cope with Stigma." American Journal of Public Health 101 (6): 1004-1010. doi:10.2105/AJPH.2010.202838

Criminal Law (Codification and Reform) Act. 2004. Government of Zimbabwe. https://zimlii.org/zw/legislation/numact/2004/23/Criminal\%20Law\%20\%28Codification\%20and\%20Reform\%29\% 20Act\%20\%5BChapter\%209-23\%5D.pdf

Duff, N. 2018. Gay Teacher in Zimbabwe Faces Angry Demands to Resign After Coming Out to Students. Pink News. 25th September 2018. https://www.pinknews.co.uk/2018/09/25/schoolteacher-zimbabwe-attacked-comingout-students/

Duffy, L. 2005. "Suffering, Shame, and Silence: The Stigma of HIVIAIDS." Journal of the Association of Nurses in AIDS Care 16 (1): 13-20. doi:10.1016/j.jana.2004.11.002

Epprecht, M. 2013. "The Making of 'African Sexuality': Early Sources, Current Debates." In Sexual Diversity in Africa, edited by S.N. Nyeck and M. Epprecht, 54-66. Montreal: McGill-Queen's University Press.

Epprecht, M. 2012. "The Constitution Process and Sexual Minority Rights in Zimbabwe." 21 June,Solidarity Peace Trust. http://www.solidaritypeacetrust.org

Epprecht, M. 2005. "Black Skin, 'Cowboy' Masculinity: A Genealogy of Homophobia in the African Nationalist Movement in Zimbabwe to 1983." Culture, Health \& Sexuality 7 (3): 253-266. doi:10.1080/13691050410001730243

Epprecht, M. 2004. Hungochani: The History of Dissident Sexuality in Southern Africa. Montreal and Kingston: McGill-Queen's University Press. 
Epprecht, M. 1999. "The Gay Oral History Project in Zimbabwe: Black Empowerment, Human Rights, and the Research Process." History in Africa 26: 25-41. doi:10.2307/3172136

Epprecht, M. 1998. "The 'Unsaying' of Indigenous Homosexualities in Zimbabwe: Mapping a Blindspot in an African Masculinity." Journal of Southern African Studies 24 (4): 631-651. doi:10.1080/03057079808708594

Fay, H., S. D. Baral, G. Trapence, F. Motimedi, E. Umar, S. lipinge, F. Dausab, A. Wirtz, and C. Beyrer. 2011. "Stigma, Health Care Access, and HIV Knowledge among Men Who Have Sex with Men in Malawi, Namibia, and Botswana." AIDS \& Behaviour 15 (6): 1088-1097. doi:10.1007/s10461-010-9861-2

Fekete, E. M., S. L. Williams, and M. D. Skinta. 2018. "Internalised HIV-Stigma, Loneliness, Depressive Symptoms and Sleep Quality in People Living with HIV." Psychology \& Health (33) (3): 398-415. doi:10.1080/08870446.2017.1357816

Ferris, F. N., S. H. Macdonald, R. M. Conroy, P. Chiroro, D. Ni Cheallaigh, M. Nyamucheta, B. Mapanda, G. Shumba, D. Mudede, and E. Byrne. 2019. "We Are the Change'-an Innovative Community-Based Response to Address Self-Stigma: A Pilot Study Focusing on People Living with HIV in Zimbabwe." PLoS ONE 14 (2): e0210152. doi:10.1371/journal.pone.0210152

Fitzgerald-Husek, A., M. J. Van Wert, W. F. Ewing, A. L. Grosso, C. E. Holland, R. Katterl, L. Rosman, A. Agarwal, and S. D. Baral. 2017. "Measuring Stigma Affecting Sex Workers (SW) and Men Who Have Sex with Men (MSM): a Systematic Review." PLoS One 12 (11): e0188393. doi: 10.1371/journal.pone.0188393

Gunda, M. R. 2010. Homosexuality and the Bible in Zimbabwe, Bamberg: University of Bamberg Press.

Gunda, M. R. 2011. "Gender Prejudice in the Use of Biblical Texts against Same-Sex Relationships in Zimbabwe." Journal of Gender and Religion in Africa 17 (2): 93-108.

Goddard, K. 2004. "Fair Representation, GALZ and the History of Gay Movement in Zimbabwe." Journal of Gay \& Lesbian Social Services 16 (1): 75-98. doi:10.1300/J041v16n01_05

Goffman, E. 1963. Stigma: Notes on the Management of Spoiled Identity. Englewood Cliffs, NJ: Prentice Hall.

Haghdoost, A., and M. Karamouzian. 2012. "Zero New HIV Infections, Zero Discrimination, and Zero AIDS-Related Deaths: Feasible Goals or Ambitious Visions on the Occasion of the World AIDS Day?" International Journal of Preventive Medicine 3 (12): 819-823. doi:10.4103/2008-7802.104850

Hunt, J., K. Bristowe, S. Chidyamatare, and R. Harding. 2017. "They Will Be Afraid to Touch You': LGBTI People and Sex Workers' Experiences of Accessing Healthcare in Zimbabwe-an in-Depth Qualitative Study." BMJ Global Health 2 (2): e000168-8. doi:10.1136/bmjgh-2016-000168 
Kharsany, A. B. M., and Q. A. Karim. 2016. "HIV Infection and AIDS in Sub-Saharan Africa: Current Status, Challenges and Opportunities." The Open AIDS Journal 10 (1): 34-48. doi:10.2174/1874613601610010034

Lane, T., T. Mogale, H. Struthers, J. Mclntyre, and S. M. Kegeles. 2008. "They See You as a Different Thing: The Experiences of Men Who HaveS with Men with Healthcare Workers in South African Township Communities." Sexually Transmitted Infections 84 (6): 430-433. doi:10.1136/sti.2008.031567

Larsson, M., J. M. Shio, M. W. Ross, and A. Agardh. 2017. "Acting within an Increasingly Confined Space: A Qualitative Study of Sexual Behaviours and Healthcare Needs among Men Who Have Sex with Men in a Provincial Tanzanian City." PLoS One 12 (8): e0183265-18. doi:10.1371/journal.pone.0183265

Link, B. G., and J. C. Phelan. 2001. "Conceptualizing Stigma." Annual Review of Sociology 27 (1):363-385. doi:10.1146/annurev.soc.27.1.363

Mabvurira, V., P. D. Motsi, T. Masuka, and E. E. Chigondo. 2012. "The 'Politics' of Sexual Identities in Zimbabwe: A Social Work Perspective?" International Journal of Humanities and Social Sciences 2 (13): 218-223.

Maleke, K., N. Makhakhe, R. P. H. Peters, G. Jobson, G. De Swardt, J. Daniels, T. Lane, J. A. McIntyre, J. Imrie, and H. Struthers. 2017. "HIV Risk and Prevention among Men Who Have Sex with Men in Rural South Africa." African Journal of AIDS Research 16 (1): 31-38. doi: 10.2989/16085906.2017.1292925

Matsikure, S. 2009. "A Bird's Eye-View of HIV and Gay and Lesbian Issues in Zimbabwe." In From Social Silence to Social Science Same-Sex Sexuality, HIV \& AIDS and Gender in South Africa, edited by V., Reddy, T., Sandfort and L., Rispel, 143-146. Pretoria: HSRC Press.

Maulsby, C., G. Millett, K. Lindsey, R. Kelley, K. Johnson, D. Montoya, and D. Holtgrave. 2014. "HIV among Black Men Who Have Sex with Men (MSM) in the United States: A Review of the Literature." AIDS \& Behavior 18 (1): 10-25. doi:10.1007/s10461-013-0476-2

McIntyre, J. A. 2010. "The Need for HIV Prevention Interventions for Men Who Have Sex with Men in Africa." Sexually Transmitted Infections 86 (2): 82-83. doi:10.1136/sti.2009.041640

Ministry of Health and Child Care. 2018. Promoting Health for all: Participants Handbook for Healthcare Providers Focusing on Key Populations. Harare: Southern Africa HIV and AIDS Information Dissemination Service (SAfAIDS).

Ministry of Health and Child Care \& National AIDS Council. Zimbabwe. 2015. "Extended Zimbabwe National HIV and AIDS Strategic Plan 2015-2020." Harare: Ministry of Health and Child Care \& National AIDS Council. http://procurementnotices.undp.org/view_file.cfm?doc_id=114051

Moen, K., P. Aggleton, M. T. Leshabari, and A. Middelthon. 2012. "Not at All so Hardto-Reach: Same-Sex Attracted Men in Dar Es Salaam." Culture, Health \& Sexuality 14 (2): 195-208. doi:10.1080/13691058.2011.632825 
Muparamoto, N. 2018. Understanding Defiant Identities: An Ethnography of Gays and Lesbians in Harare, Zimbabwe. Rhodes University: South Africa. http://vital.seals.ac.za:8080/vital/access/manager/Repository/vital:29133

National Library of Medicine. 2002. Greek Medicine: The Hippocratic Oathhttps://www.nlm.nih.gov/hmd/greek/greek_oath.html

New Zimbabwe. 2018., "ED Courts Gay Vote as ZANU PF in a Surprise Meeting with LGBT Representatives." Retrieved on 22 June 2018 from https://www.newzimbabwe.com/ed-courtsgay-vote-aszanu-pf-in-surprise-meetingwith-lgbt-reps/

Nkambule, R., H. Nuwagaba-Biribonwoha, Z. Mnisi, C. Ginindza, Y.T. Duong, H. Patel, S. Saito, N.M. Philip, K. Brown, C. Draghi., et al. 2017. "Substantial Progress in Confronting the HIV

Epidemic in Swaziland: First Evidence of National Impact." http://programme.ias2017.org/Abstract/Abstract/5837

Ntata, P. R., A. S. Muula, and S. Siziya. 2008. "Socio-Demographic Characteristics and Sexual Health Related Attitudes and Practices of Men Having Sex with Men in Central and Southern Malawi." Tanzania Journal of Health Research 10 (3): 124-130. doi:10.4314/thrb.v10i3.14351

Nyanzi, S. 2013. "Rhetorical Analysis of President Jammeh's Threats to Behead Homosexuals in the Gambia." In Sexual Diversity in Africa, edited by S.N Nyeck and M. Epprecht, 67-87. Montreal: McGill-Queen's University Press.

O'Brien, S., and A. Broom. 2014. "HIV in Harare: The Role and Relevance of Social Stigma." African Journal of AIDS Research 13 (4): 339-349. doi:10.2989/16085906.2014.961941

Parker, C., J. S. Hirsch, M. M. Philbin, and R. J. Parker. 2018. "The Urgent Need for Research and Interventions to Address Family-Based Stigma and Discrimination against Lesbian, Gay, Bisexual, Transgender, and Queer Youth." Journal of Adolescent Health 63 (4): $383 . \quad$ S1054-139X(18)30201-5. doi:10.1016/j.jadohealth.2018.05.018

Phillips, O. 2009. "Blackmail in Zimbabwe: Troubling Narratives of Sexuality and Human Rights." The International Journal of Human Rights 13 (2-3): 345-364. doi:10.1080/13642980902758192

Phillips, O. 1997. "Zimbabwean Law and the Production of a White Man's Disease." Social \& Legal Studies 6 (4): 471-491. doi:10.1177/096466399700600402

Ross, M. W., J. Nyoni, M. Larsson, J. Mbwambo, A. Agardh, J. Kashiha, and S. A. McCurdy. 2015. "Health Care in a Homophobic Climate: The SPEND Model for Providing Sexual Health Services to Men Who Have Sex with Men Where Their Health and Human Rights Are Compromised." Global Health Action 8 (1): 26096. doi:10.3402/gha.v8.26096 
Shoko, T. 2010. 'Worse than Dogs and Pigs?' Attitudes toward Homosexual Practice in Zimbabwe." Journal of Homosexuality 57 (5): 634-649. doi:10.1080/00918361003712087

Smith, R. P., and S. Mafa. 2010. Zimbabwe Nurses Association Presentation. Regional Network of National Nurses Organisations in Southern Africa with Labour Union Status, 11-14 February 2010, Swaziland. Retrieved on 20 June 2018 from https://slideplayer.com/slide/5689925/

Stojisavljeciv, S.,. B. Djikanovic, and B. Matejic. 2017. "The Devil Has Entered You': A Qualitative Study of Men Who Have Sex with Men (MSM) and the Stigma and Discrimination They Experience from Healthcare Professionals and the General Community in Bosnia And Herzegovina." PLoS ONE 12 (6): e0179101. doi:10.1371/journal.pone.0179101

UNAIDS. 2016 . HIV Prevention Among Key Populations. Geneva, UNAIDS.

http://www.unaids.

org/en/resources/presscentre/featurestories/2016/november/20161121_keypops

UNAIDS. 2017a. Towards Ending AIDS in Eastern and Southern Africa Region: Leaving No One Behind. Geneva: UNAIDS.

UNAIDS. 2017b. Zimbabwe. http://www.unaids.org/en/regionscountries/countries/zimbabwe

Van Klinken, A., and E. Chitando. 2016. Public Religion and the Politics of Homosexuality in Africa. New York: Ashgate Publishing.

Van Klinken, A., and M. R. Gunda. 2012. "Taking up the Cudgels against Gay Rights? Trends and Trajectories in African Christian Theologies on Homosexuality." Journal of Homosexuality 59 (1): 114-138. doi:10.1080/00918369.2012.638549

World Medical Association. 2006. "WMA International Code of Medical Ethics." https://www.wma. net/policies-post/wma-international-code-of-medical-ethics/ 